\title{
The Production of Soluble and Cellular Interleukin-2 Receptors by Cord Blood Mononuclear Cells following In Vitro Activation
}

\author{
DAVID L. NELSON, CAROLE C. KURMAN, MARY E. FRITZ, BERNARD BOUTIN, AND \\ LAURENCE A. RUBIN \\ Immunophlysiology Section, Metabolism Branch, National Cancer Institute. National Institutes of Ifealth, \\ Bethesda, Maryland 20205
}

\begin{abstract}
Cord blood mononuclear cells (CBMC) were investigated for their capacity to generate both cellular and soluble, supernatant interleukin-2 receptors (IL-2R) following cellular activation in vitro. Soluble IL-2R were measured in cell-free supernatants and in detergent-solubilized cell extracts with a "sandwich" enzyme-linked immunosorbent assay. CBMC and adult peripheral blood mononuclear cells were activated with phytohemagglutinin or the murine monoclonal antibody OKT3. CBMC and adult peripheral blood mononuclear cells generated cellular and soluble $I L-2 R$ in response to both activators. Peak values for supernatant IL-2R were observed on day 7 , while peak values of cell-associated IL-2R occurred on day 5 , followed by a decline on day 7 . With the exception of supernatant IL-2R production induced by OKT3 stimulation, CBMC produced $\mathrm{IL}-2 \mathrm{R}$ in amounts comparable to adult mononuclear cells. Cord blood plasma also contained amounts of IL-2R comparable to that found in adult sera/ plasma. Thus, CBMC appear largely immunocompetent with regard to the expression of IL-2R. (Pediatr Res 20: 136-139, 1986)
\end{abstract}

\section{Abbreviations}

CBMC, cord blood mononuclear cells

IL-2, interleukin-2

IL-2 $R$, interleukin-2 receptor(s)

FCS, fetal calf serum

PBMC, peripheral blood mononuclear cells

PBS, phosphate buffered saline

PHA, phytohemagglutinin

The immune responsiveness of neonatal $T$ cells appears relatively well developed. Neonatal T cells proliferate in response to polyclonal activators such as phytohemagglutinin (PHA) (1) and also to certain antigens such as cell-associated alloantigens (2). Neonatal $T$ cells are also capable of providing both help and suppression for B-cell immunoglobulin responses induced by polyclonal activators $(3,4)$ and also help and suppression for specific antibody responses by allogeneic B cells induced by antigens in vitro (5). Nconatal $T$ cells are capable of inhibiting proliferative responses of adult $\mathrm{T}$ cells to certain stimuli-presumably through both cellular and soluble mechanisms $(6,7)$.

Received July 1. 1985: accepted September 18.1985.

Correspondence and reprint requests should be addressed to David L. Nelson. M.D.. Bldg. 10, Rm. 4N112. Vational Institutes of Health. Bethesda, MD 2089?.

Acknowledgement: L.A.R. supported by a Fellowship from the Arthritis Society of Canada.
Recently, the role of the lymphokine IL-2 in immune responses has been under intense investigation (8). IL-2, which supports the proliferation of activated T cells and B cells (9), is secreted in normal amounts by PHA-activated neonatal $\mathrm{T}$ cells (10). While the normal proliferative responses noted above suggest that IL-2 expression might be normal in neonatal T cells, some controversy exists as to the presence of IL-2-independent mechanisms of T-cell proliferation (11) which might be employed by neonatal $\mathrm{T}$ cells. Therefore, we undertook an analysis of the expression of IL-2R by activated neonatal mononuclear cells in vitro using a newly developed enzyme-linked immunosorbent assay to quantitatively measure both cellular and released IL-2R.

\section{MATERIALS AND METHODS}

Preparation of cord blood and adult peripheral blood mononuclear cells. CBMC and PBMC were prepared as previously described in detail by centrifugation on Ficoll-Hypaque gradients (5). Cord blood plasma and adult plasma were prepared by centrifugation of heparinized whole blood.

Antibodies. The murine monoclonal anti-IL-2R antibody termed anti-Tac (12) was the generous gift of Dr. T. A. Waldmann, NIH. The murine monoclonal anti-IL-2R, 7G7B6, which binds to the IL-2R at an epitope distinct from anti-Tac and IL2 , was produced and modified with fluorescein isothiocyanate as described (13).

Cell cultures and stimulants. Cultures of CBMC and adult PBMC containing $1 \times 10^{6}$ mononuclear cells in $2 \mathrm{ml}$ of RPMI 1640 supplemented with $10 \%$ fetal calf serum (FCS), penicillin $100 \mathrm{U} / \mathrm{ml}$, and streptomycin $100 \mu \mathrm{g} / \mathrm{ml}$ were established in individual wells of 24-well plates (Costar). Triplicate cultures were incubated for various times in a humidified atmosphere of $5 \% \mathrm{CO}_{2}$ in air at $37^{\circ} \mathrm{C}$. Cultures were either unstimulated (media alone), or they contained PHA (GIBCO) at a final dilution of $1 /$ 200 or the murine monoclonal antibody OKT3 (Ortho) at a final concentration of $10 \mu \mathrm{g} / \mathrm{ml}$. Cultures were harvested by centrifugation at $550 \times g$ for $10 \mathrm{~min}$ and the supernatants removed. The remaining cells were washed once in Dulbecco's phosphate buffered saline (PBS) containing $25 \mathrm{mM}$ Tris pH 7.4. The cell pellet was solubilized in $0.5 \mathrm{ml}$ of PBS containing $25 \mathrm{mM}$ Tris pH 7.4 containing $1 \%$ Triton $\mathrm{X}-100$, followed by centrifugation in a microfuge (EPPENDORF) for 5 min and recovery of the supernatant. Culture supernatants and detergent-solubilized cell extracts were stored at $-20^{\circ} \mathrm{C}$ until assayed for IL-2R.

Enzyme-linked immunosorbent assay for the measurement of $I L-2 R$. The enzyme-linked immunosorbent assay for soluble IL$2 \mathrm{R}$ was performed as described in detail (14). In brief, alternate columns of the inner 60 wells of microtiter plates were coated with $150 \mu \mathrm{l}$ of the monoclonal anti-IL-2R antibody, anti-Tac, suspended in carbonate buffer $\mathrm{pH} 9.6$ at a concentration of 1 
$\mu \mathrm{g} / \mathrm{ml}$ or buffer alone. Following overnight incubation, the plates were washed and $100 \mu \mathrm{l}$ of sample was added to coated and control wells. Following a 2 -h incubation at room temperature, the plates were washed and all wells received $100 \mu \mathrm{l}$ of a 1:4000 dilution of fluorescein isothiocyanate-modified 7G7B6 in PBS containing Tween and $1 \%$ FCS (PBS/Tween/FCS). After a 2-h incubation, the plates were washed and $100 \mu \mathrm{l}$ of a 1:1000 dilution of alkaline phosphatase-conjugated rabbit anti-fluorescein isothiocyanate in PBS/Tween/FCS added to all wells. After an additional $1-\mathrm{h}$ incubation, p-nitrophenyl phosphate $(1 \mu \mathrm{g} / \mathrm{ml}$, Sigma) in diethanolamine buffer $\mathrm{pH} 9.8$ was added and the absorbance of the control wells was subtracted from the experimental wells; this absorbance value was compared to absorbances determined for a standard curve generated by the addition of varying amounts of IL-2R as previously described (15). The IL$2 \mathrm{R}$ standard was the cell-free supernatant of an in vitro passaged $\mathrm{T}$-cell line which was assigned a level of $1000 \mathrm{IL}-2 \mathrm{R} / \mathrm{ml}$.

Calculations. Geometric means and SEM were calculated for the responses of groups of donors, and those values less than 62.5 were assigned a value of 62.5 for the purposes of calculations. Different groups were compared using Student's $t$ test for nonpaired values.

\section{RESULTS}

Cellular and supernatant $I L-2 R$ generation by $C B M C$ and $P B M C$ with various stimuli. Previous studies of IL-2R generation by activated adult PBMC revealed that cellular IL-2R expression peaked on days $3-5$ of culture while soluble supernatant IL-2R levels were maximal on day 7 of culture (14). Therefore, we first examined the cellular IL-2R production of stimulated CBMC and adult PBMC on day 5 of culture. As can be seen in Table 1, when CBMC and adult PBMC were stimulated with PHA or the murine monoclonal antibody OKT3, the cells of all donors expressed IL-2R on day 5 of culture. Cells from some donors made IL-2R when stimulated with culture medium alone. There were differences among both adult and neonatal individuals in terms of the capacity to generate IL-2R, and "high responders"

Table 1. Stimulus employed to generate cellular IL-2R*

\begin{tabular}{|c|c|c|c|}
\hline Donor & Media & PHA & OKT3 \\
\hline $\operatorname{CBMC} \propto 1$ & $<62.5$ & 766.8 & 246.2 \\
\hline CBMC $\& 2$ & 103.9 & 8474.7 & 881.7 \\
\hline CBMC \& 3 & $<62.5$ & 1583.9 & 601.4 \\
\hline $\mathrm{CBMC} \alpha 4$ & $<62.5$ & 5030.0 & 679.0 \\
\hline CBMC \& 5 & $<62.5$ & 2042.2 & 378.7 \\
\hline CBMC \& 6 & $<62.5$ & 1923.7 & 818.9 \\
\hline Mcan & 68.0 & 2424.6 & 549.5 \\
\hline$(\times / \div$ SEM $)$ & $(1.1)$ & $(1.4)$ & $(1.2)$ \\
\hline PBMC \& 1 & 150.2 & 1928.2 & 1159.7 \\
\hline PBMC \& 2 & $<62.5$ & 608.2 & 635.5 \\
\hline $\operatorname{PBMC} \propto 3$ & 99.8 & 3246.5 & 1129.3 \\
\hline $\operatorname{PBMC} \& 4$ & $<62.5$ & 222.5 & 492.1 \\
\hline $\operatorname{PBMC} \propto \alpha 5$ & $<62.5$ & 601.2 & 544.5 \\
\hline PBMC $\& 6$ & 70.9 & 1053.4 & 538.0 \\
\hline $\begin{array}{l}\text { Mean } \\
(\times / \div \text { SEM })\end{array}$ & $\begin{array}{l}79.9 \\
(1.2)\end{array}$ & $\begin{array}{l}901.4 \\
(1.5)\end{array}$ & $\begin{array}{l}702.3 \\
(1.2)\end{array}$ \\
\hline Significance & $p>0.3$ & $p>0.1$ & $p>0.3$ \\
\hline
\end{tabular}

* Cellular IL-2R expression by CBMC and adult PBMC following activation with various stimuli. CBMC and PBMC were cultured in vitro with media. PHA, or OKT3 for 5 days. The cells were washed once in PBS containing $25 \mathrm{mM}$ Tris pH 7.4 (TBS) and solubilized in TBS containing $1 \%$ Triton X-100. The amount of IL-2R in the detergentsolubilized cell extracts was determined using an enzyme-linked immunosorbent assay (see "Materials and methods").
Table 2. Stimulus used to generate supernatant IL-2R*

\begin{tabular}{cccc}
\hline Donor & Media & PHA & OKT3 \\
\hline CBMC $\alpha 1$ & $<62.5$ & 285.9 & 102.4 \\
CBMC $\alpha 2$ & $<62.5$ & 2619.2 & 432.4 \\
CBMC $\alpha 3$ & $<62.5$ & 1010.9 & 377.9 \\
CBMC $\alpha 4$ & $<62.5$ & 3270.6 & 204.5 \\
CBMC $\alpha 5$ & $<62.5$ & 1797.7 & 206.2 \\
CBMC $\alpha 6$ & $<62.5$ & 1317.7 & 420.3 \\
Mean & $<62.5$ & 1342.8 & 258.3 \\
$(\times / \div$ SEM) & & $(1.4)$ & $(1.2)$ \\
PBMC $\alpha 1$ & 154.8 & 1559.1 & 1447.2 \\
PBMC $\alpha 2$ & $<62.5$ & 1052.0 & 593.1 \\
PBMC $\alpha 3$ & 189.4 & 3437.0 & 1410.9 \\
PBMC $\alpha 4$ & $<62.5$ & 391.0 & 655.6 \\
PBMC $\alpha 5$ & 85.8 & 1012.7 & 654.4 \\
PBMC $\alpha 6$ & 78.0 & 1201.2 & 592.2 \\
Mean & & & \\
$(\times / \div$ SEM) & $(1.2)$ & 1178.6 & 821.6 \\
\end{tabular}

Significance $\quad p>0.05 \quad p>0.5 \quad p<0.01$

* Supernatant IL-2R production by CBMC and adult PBMC. CBMC and adult PBMC were cultured in vitro with media. PHA, or OKT3 for 7 days. The supernatants were harvested and the amount of soluble IL$2 \mathrm{R}$ in the supernatant was determined using an enzyme-linked immunosorbent assay (see "Materials and methods").

tended to make larger quantities of cellular IL-2R with all stimuli, including media alone. With all of the stimuli tested, there were no significant differences between adult and neonatal mononuclear cells for the generation of cell-associated IL-2R. When the supernatants of these same 5-day cultures were examined for soluble IL-2R, the mean $(\mathrm{x} / \div \mathrm{SEM})$ values were as follows: CBMC-media 63.5 (1.0), PHA 1275 (1.5), OKT3 271 (1.3); PBMC-media 58.9 (1.1), PHA 923 (1.4), and OKT3 725 (1.2). Again, for each stimulus tested, there was no statistically significant difference $(p<0.01)$ between CBMC and adult PBMC. We next examined the levels of soluble IL-2R in the supernatant of day 7 cultures from these same individuals. As can be seen in Table 2, activated CBMC and PBMC all produced measurable IL-2R. Those individuals who had generated the most cellassociated IL-2R on day 5 also produced the most supernatant IL-2R on day 7. With the exception of the response to OKT3, there were no significant differences between CBMC and PBMC with regard to the generation of soluble IL-2R on day 7 following activation. When the cells from four of the CBMC and four of the PBMC were studied for cell-associated IL-2R on day 7 , the mean $(\mathrm{x} / \div \mathrm{SEM})$ values were as follows: CBMC-media 62.5 (1.0), PHA 773 (1.4), OKT3 151 (1.6); PBMC-media 151 (1.3), PHA 509 (1.4), OKT 289 (1.1). Again, no statistically significant $(p<0.01)$ differences existed between CBMC and adult PBMC

Time course of cellular and supernatant $I L-2 R$ production following cellular activation. While these studies of cellular and supernatant IL-2R production on days 5 and 7 , respectively, suggested that neonatal mononuclear cells were reasonably competent with regard to the production of IL-2R, we undertook experiments to see if the time course of cellular and supernatant IL-2R generation might be temporally different for CBMC as opposed to adult PBMC. When six freshly isolated CBMC and adult PBMC were examined for cellular IL-2R, no IL-2R could be measured (all samples $<62.5 \mathrm{U} / \mathrm{ml}$ ). As can be seen in Figure 1 , the expression of cellular IL-2R at various time points following activation with PHA was similar in CBMC and adult PBMC. In addition, the generation of supernatant IL-2R at various intervals following activation of these same cells (Fig. 1, right panel) was comparable in CBMC and adult PBMC. 

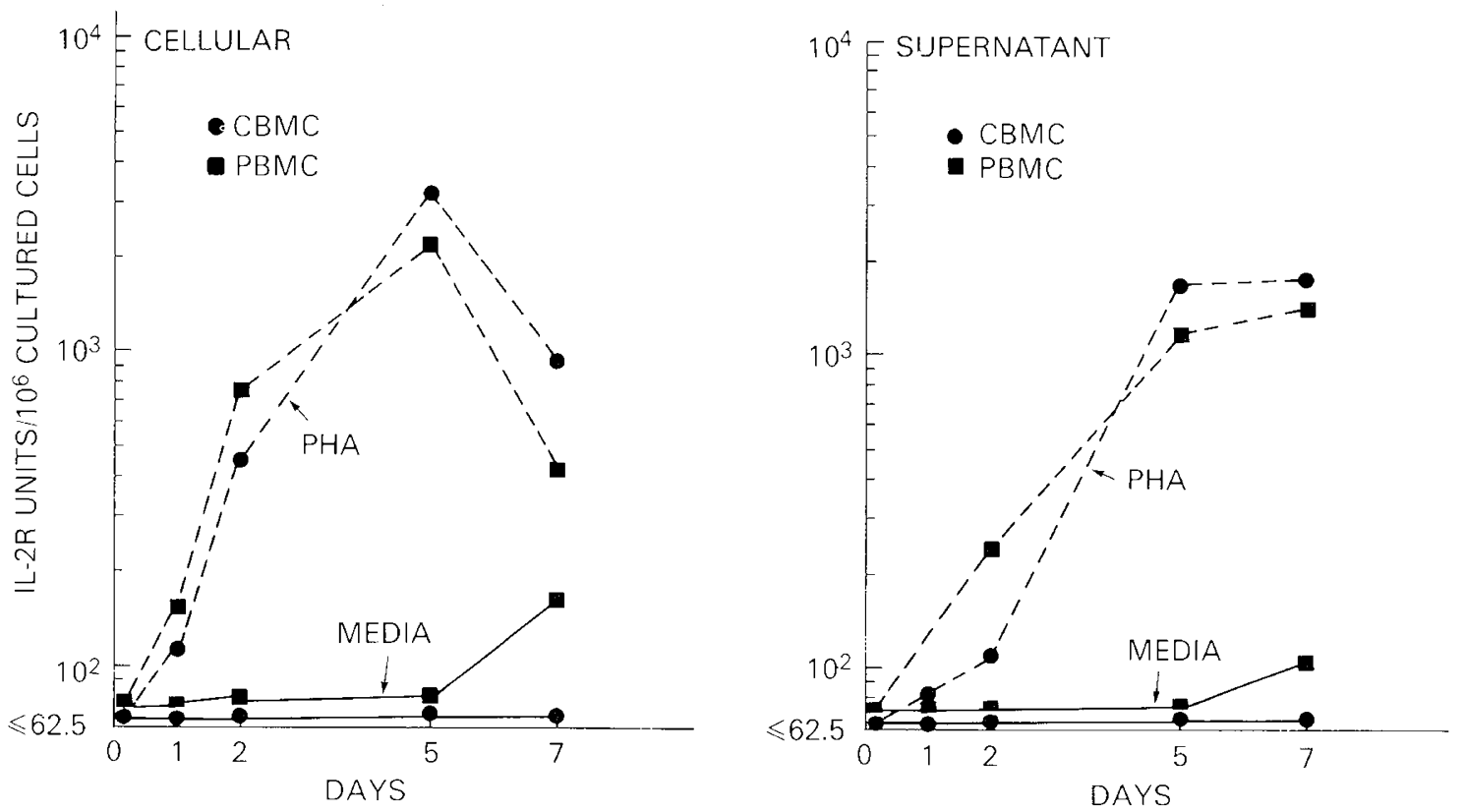

Fig. 1. Time course of cellular and supernatant IL-2R production by PHA-activated CMBC and adult PBMC in vitro. CBMC (-) and PBMC ) were cultured with media alone (-) or PHA $(---)$ for various time periods in vitro. Detergent-solubilized cells (left $)$ and cell-free culture supernatants (right) were analyzed for IL-2R by enzyme-linked immunosorbent assay (see "Materials and methods").

Levels of IL-2R in cord blood plasma. As normal adults possess resting serum/plasma levels of IL-2R (Rubin LA, Kurman CC, Fritz. ME, Yarchoan R, Nelson DL, unpublished data), we determined the plasma levels of IL-2R in cord blood plasma. The mean $(\mathrm{x} / \div \mathrm{SEM})$ plasma IL-2R level in eight cord blood plasma samples was $499(x / \div 1.1)$ with a range of $335-760$, a value not significantly different $(p>0.1)$ than that of 19 normal adults, mean $=548(x / \div 1.2)$, with a range of $155-1640$.

\section{DISCUSSION}

In the present studies we have examined the capacity of CBMC to generate both cell-associated and released soluble IL-2R in vitro. Freshly isolated CBMC like normal adult PBMC did not express measurable IL-2R prior to activation, and cord blood plasma contained levels of soluble IL-2R comparable to adult plasma. Following cellular activation in vitro with PHA and the murine monoclonal antibody OKT3 reacting with the $\mathrm{T}$-cell antigen receptor complex, CBMC produced both cellular and supernatant IL-2R. The amounts of IL-2R produced were comparable to those made by adult mononuclear cells, with the exception that CBMC produced significantly less supernatant soluble IL-2R when stimulated with OKT3. No differences were observed between cord blood mononuclear and adult cells in the kinetics of IL-2R production following PHA stimulation.

Recent studies have demonstrated that IL-2 plays a critical role in the maturation and regulation of the immune response (8). Previous studies had demonstrated that IL-2 production by PHA-stimulated cord blood cells is normal (10). The normal proliferative responses observed with CBMC suggested that IL$2 \mathrm{R}$ expression by such cells might be normal. Our interest, however, was in whether CBMC might produce increased amounts of cellular and/or soluble IL-2R following activation. As the released in vitro soluble IL-2R is capable of binding IL-2 (Rubin LA, Jay G, Nelson DL, unpublished data), these molecules are candidates for mediating immunosuppression, a phenomenon well recognized with CBMC $(5-7,10)$. In addition, our previous studies using the monoclonal antibody $7 \mathrm{G} 7 \mathrm{~B} 6$ and flow microfluorimetry suggested that CBMC produced more cellular IL-2R than adult mononuclear cells (16). In the present studies we found that with PHA activation, CBMC produced cellular and supernatant IL-2R levels comparable to adult cells, and with OKT3 stimulation the production of cellular but not supernatant IL-2R was equivalent to adult cells. These differences might be due to the fact that PHA and OKT3 stimulate T cells via different cell surface molecules $(17,18)$, or alternatively, may relate to the fact that OKT3 stimulates cells via the T-cell antigen receptor-a complex which may not be fully functional in neonatal $T$ cells. It should be stressed, however, that the differences were only observed for supernatant IL-2R and that all CBMC made supernatant IL-2R. In addition, it should be pointed out that the IL-2R present in the culture supernatants from CBMC is known only to be immunoreactive receptor, and studies are planned to attempt to compare the binding affinity of the soluble IL-2R from CBMC and adult PBMC. In soluble form, OKT3 stimulation of T cells is monocyte dependent (19). The present results suggest that this monocyte function is largely normal among neonatal monocytes, a finding consistent with previous work on antigen presentation by such cells $(20,21)$. The present studies with OKT3 suggest that activation of neonatal $T$ cells through the antigen receptor complex is possible and such activated cells express normal amounts of IL-2R. However, these activated cells may release less IL-2R than adult cells. The mechanism(s) for this hyporesponsiveness remain to be elucidated. Previously we had interpreted the levels of IL-2R in the serum/plasma of normal healthy adults as being the result of ongoing stimulation of the immune system with everyday exposure to exogenous antigens (Rubin LA, unpublished data). The finding of plasma levels of IL-2R in cord blood comparable to adults suggests that this IL-2 might be the result of lymphopoiesis or be of maternal origin rather than exogenous antigenic stimulation. Abnormal levels of plasma or serum levels of IL-2R in pediatric patients might therefore be indicative of immunodeficiency diseases and/or lymphoproliferative disorders.

\section{REFERENCES}

1. Campbell AC. Waller C. Wood J, Aynsley-Green A. Yu V 1974 Lymphocyte subpopulations in the blood of newborn infants. Clin Exp Immunol 18:469482

2. Granberg C. Manninen K. Tojvanen P 1976 Cell mediated lympholysis by human neonatal lymphocytes. Clin Immunol Immunopathol 6:256-263 
3. Hayward AR, Lawton AR 1977 Induction of plasma cell differentiation of human fetal lymphocyles: evidence for functional immaturity of $\mathrm{T}$ and $\mathrm{B}$ cells. J Immunol 119:1213-1217

4. Tosato G. Magrath IT, Koski IR. Dooley NJ. Blaese RM 1980 B-cell differcntiation and immunoregulatory T-cell function in human cord blood lymphoyetes. J Clin Invest 66:383-388

5. Yarchoan R. Nelson DL 1983 A studv of the functional capabilities of human neonatal lymphocytes for in vitro specific antibody production. J Immuno 131:1222-1228

6. Oldstone MBA. Tishon $\Lambda$. Moretta L 1977 Active thymus derived suppresso lymphocytes in human cord blood. Nature 269:333-335

7. Olding LB. Murgita RA. Wigzell H 1977 Mitogen-stimulated lymphoid cells from human newborns suppress the proliferation of maternal lymphocytes across a cell-impermeable membrane. J Immunol 119:1109-1114

8. Cantrell D^. Smith $\mathrm{K} \wedge 1984$ The interlcukin-2 T-cell system: a new cel growth model. Science 224:1312-1316

9. Waldmann TA. Goldman CK. Robb RJ, ct al. 1984 Expression of interleukin2 receptors on activated human B-cells. J Exp Med 160:1450-1466

10. Hayward $A R$, Kurnick J 1981 Newborn $T$ cell suppression: early appearance. maintenance in culture and lack of growth factor suppression. $\mathrm{J}$ Immuno $126: 50-53$

11. Koretzky GA. Danicle RP. Greene WC. Nowell PC 1983 Evidence for an interleukin-independent pathway for human lymphocyte activation. Proc Natl Acad Sci USA 80:3444-3447

12. Uchiyama T, Broder SA. Waldmann TA 1981 A monoclonal antibody reactive with activated and functionally mature human T cells. J Immunol 126:1393 1397

13. Rubin LA, Kurman CC, Biddison WF. Goldman ND. Nelson DL 1985 A monoclonal antibody, $7 \mathrm{G} 7 / \mathrm{B} 6$, that binds to an epitope on the human IL-2 receptor distinct from that recognized by IL-2 or anti-Tac. Hvbridoma 4:91102

14. Rubin LA. Kurman CC, Fritz ME, Biddison WE, Boutın B, Yarchoan R Nelson DL 1985 Soluble interleukin 2 receptors are released from activated human lymphoid cells in vitro. J Immunol 135:3172--3177

15. Yarchoan R. Engler. RJM. Barrow LA. Kurman CC. Nelson DL 1984 Antigen stimulated human $B$ cell clones are committed to the production of a single class of antibody in vitro. J Immunol 132:2696-2699

16. Rubin LA, Kurman CC, Biddison WE, Brown T, Goldman ND, Nelson DL 1984 Studies of the expression of a $\mathrm{T}$-cell activation antigen in primary immunodeficiency disorders and neonatal cord blood cells. In: Griscclli $\mathrm{C}$. Vossen $J$ (eds) Progress in Immunodeficiency Research and Therapy $\mathbf{I}$ Elsevier Science Publishers BV, Amsterdam. pp 103-108

17. Meuer SC, Hussey RE, Cantrell DA, Hodgdon JC, Schlossman SF, Smith KS Reinherz EL 1984 Triggering of the T3-Ti antigen-receptor complex results in clonal $\mathrm{T}$ cell proliferation through an interleukin 2-dependent autocrine pathway. Proc Natl Acad Sci USA 81:1509-1513

18. O'Flynn K. Krensky AM, Beverly PCL, Burakoff SJ, Linch DC 1985 Phytohemagglutinin activation of $T$ cells through the sheep red blood cell receptor Nature 313:686-687

19. Van Wauwe JP. DeMay JR. Goossens JG 1980 OKT3: a monoclonal antihuman T lymphocyte antibody with potent mitogenic properties. J Immunol 124:2708-2713

20. Hayward AR. Herberger J. Groothuis J, Levin MR 1984 Specific immunity after congenital or neonatal infection with cytomegalovirus or herpes simplex virus. J Immunol 133:2469-2473

21. Wakasugi N, Virelizier JL 1985 Defective IFN $\gamma$ production in the human neonate. I. Dysregulation rather than intrinsic abnormality. J Immunol 134:167-171 